\title{
Feasibility of Neurovascular Antropylorus Perineal Transposition With Pudendal Nerve Anastomosis Following Anorectal Excision: A Cadaveric Study for Neoanal Reconstruction
}

\author{
Abhijit Chandra, Ashok Kumar, M Noushif, Nitish Gupta, Vijay Kumar ${ }^{1}$, Navneet Kumar Chauhan², \\ Vishal Gupta \\ Departments of Surgical Gastroenterology, ${ }^{1}$ Plastic Surgery, and ${ }^{2}$ Anatomy, Chhatrapati Shahuji Maharaj Medical University (King George’s \\ Medical University), Lucknow, India
}

Purpose: Perineal transposition of the antropyloric valve following an anorectal excision as a substitute for a permanent colostomy has recently been reported in humans. However, the problem of neural control still remains in these patients. Our aim herein was to study the anatomical feasibility of an anastomosis between the pudendal nerve branches (inferior rectal nerve) innervating the external anal sphincter and the anterior vagal branches of the perineally-transposed antropyloric segment in cadavers.

Methods: The antropyloric segment, along with its carefully dissected branch of the anterior vagus, was mobilized based on the left gastroepiploic pedicle in six fresh human cadavers. The antropyloric valve was then transposed in the perineum after the pudendal nerve branches had been dissected out, and an approximation of these two nerves was performed to ascertain the technical feasibility of their neural anastomosis.

Results: The anterior vagus innervating the antropylorus could be harvested in all cadavers below the hepatic division of the main vagus trunk. The inferior rectal nerve or its branches were found consistently around the 3 or the 9 oclock position in the ischioanal fossa. An anatomical tension-free approximation of the anterior vagus branch (of the transposed antropyloric segment) to the inferior rectal nerve in the perineum was feasible in all the cadavers studied.

Conclusion: An inferior rectal nerve anastomosis with the anterior vagal branch of the perineally-transposed antropyloric segment can be achieved anatomically. This preliminary step can be the basis for future animal studies and subsequent clinical application of the procedure for possible neural control of the transposed antropyloric segment in the perineum.

Keywords: Anal sphincter; Colostomy; Pudendal nerve; Pylorus; Vagus nerve

\section{INTRODUCTION}

Fecal continence results from an intact anal sphincter innervated by the pudendal nerve $(\mathrm{PN})$, which causes its tonic contraction in

Received: July 25, 2012 - Accepted: October 28, 2012

Correspondence to: Abhijit Chandra, MS, MCh

Department of Surgical Gastroenterology, Chhatrapati Shahuji Maharaj Medical University (King George's Medical University), Chowk, Lucknow 226003, India

Tel: +91-522-2740068, Fax: +91-522-2256116

E-mail: abhijitchandra@hotmail.com

(C) 2013 The Korean Society of Coloproctology

This is an open-access article distributed under the terms of the Creative Commons Attribution NonCommercial License (http://creativecommons.org/licenses/by-nc/3.0) which permits unrestricted noncommercial use, distribution, and reproduction in any medium, provided the original work is properly cited. the resting state, allowing voluntary responses to defecation signals and the receptor mechanism to sense the desire to defecate [1]. End stage fecal incontinence resulting in a permanent abdominal stoma is a major morbidity. Though techniques like an intestinal smooth muscle neoanal sphincter, stimulated skeletal muscle perineal wraps and injection of autologous myoblasts (tissue engineering) have been tried, limited surgical options are available for such patients even today [2-4]. Perineal transposition of the antropyloric valve (APV) based on the left gastroepiploic artery pedicle as a substitute for a permanent stoma following an abdominoperineal resection (APR) in humans has been reported previously by us [5]. Although most after APV transposition following an APR had adequate retention of solid stools, lack of sensation and voluntary control remained a problem [6]. PN reinnervation of skeletal muscles has been performed in order to attain voluntary neosphincter 
control in canine models $[7,8]$. Both the gracilis and the gluteus maximus muscles have been used for this purpose, with the latter being more suitable for PN reinnervation and, hence, being used in humans $[1,9,10]$.

We explored the feasibility of innervating the perineally-transposed APV segment, along with its anterior vagus (AV) supply, with the inferior rectal nerve (IRN) or its branches in human cadavers. Our aim was to establish the anatomical feasibility of the procedure as a preliminary step towards future clinical application leading to possible neural control of the perineally-transposed APV segment.

\section{METHODS}

Six fresh adult cadavers (male, 3; female, 3) of North Indian origin formed the basis of this study after approval from the institutional ethics committee. The AV nerve supplying the APV segment and the IRN in the perineum (including 12 sides of perineal dissection) were carefully identified and exposed, and measurements
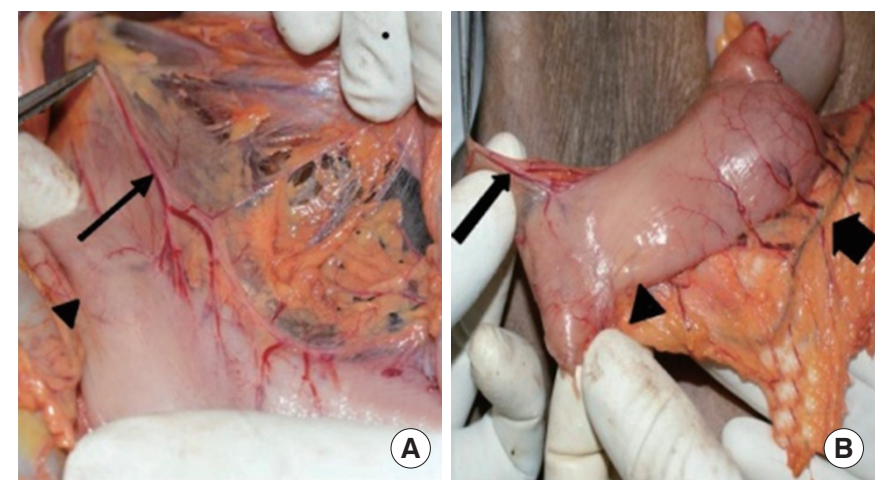

Fig. 1. (A) Abdominal dissection showing the antropyloric valve (arrow head) and the anterior vagus nerve (long arrow). (B) Pyloric branch of the anterior vagus (long arrow), gastroepiploic arcade (short arrow) and antropyloric valve (arrow head) after division of the duodenal end.
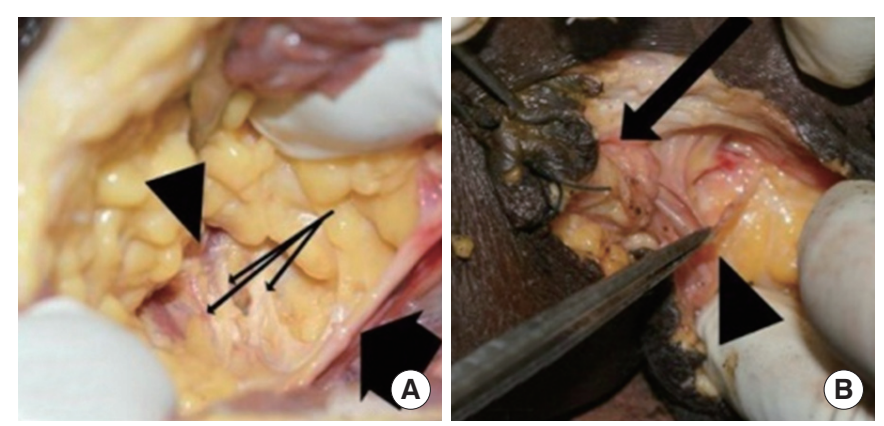

Fig. 2. (A) Gluteal approach showing the pudendal nerve (short arrow), inferior rectal nerves (long arrows) and external sphincter (arrow head). (B) Perineal dissection showing the left inferior rectal nerve (arrow head) to the external sphincter (long arrow). were made (using engineering calipers)

\section{Surgical procedure}

The dissection was carried out in the semilithotomy position. A midline abdominal incision was made from the xiphoid to the pubic symphysis, together with a circular perianal incision, after applying a purse-string suture around the anal verge. The anorectum was excised, akin to an APR operation, synchronously from above (abdomen) and below (perineum).

In the abdominal part, branches of the gastroepiploic arcade to the stomach along the greater curvature were divided, retaining the supply to the APV segment based on the left gastroepiploic artery as described previously by us $[5,11]$. The AV was carefully harvested after it gave the hepatic branch, retaining its integrity to the part of the removed antropyloric segment (Fig. 1A, B). The APV with a cuff of the first part of the duodenum and the antrum was then transposed to the perineum, along with its vascular pedicle and the AV nerve trunk.

The locations of the IRN and the branches to the external anal sphincter (EAS) were defined in separate dissections via the gluteal approach as described by O'Bichere et al. [12]. The gluteal muscles and the sacrotuberous ligament were divided, and the PN was traced after the sheath of the pudendal canal had been incised. The IRN with its branches supplying the EAS was then identified (Fig. 2A).

In the perineal part, after excision of the anorectum and the EAS, the branches of the IRN to the EAS were identified on either side (3 or 9 o'clock position) by a careful dissection in the ischioanal fossa (Fig. 2B). The APV segment with its intact gastroepiploic pedicle and harvested AV nerve was brought down to the perineum. The end of the AV nerve was then approximated with the IRN or its branches in a tension-free manner (Fig. 3).

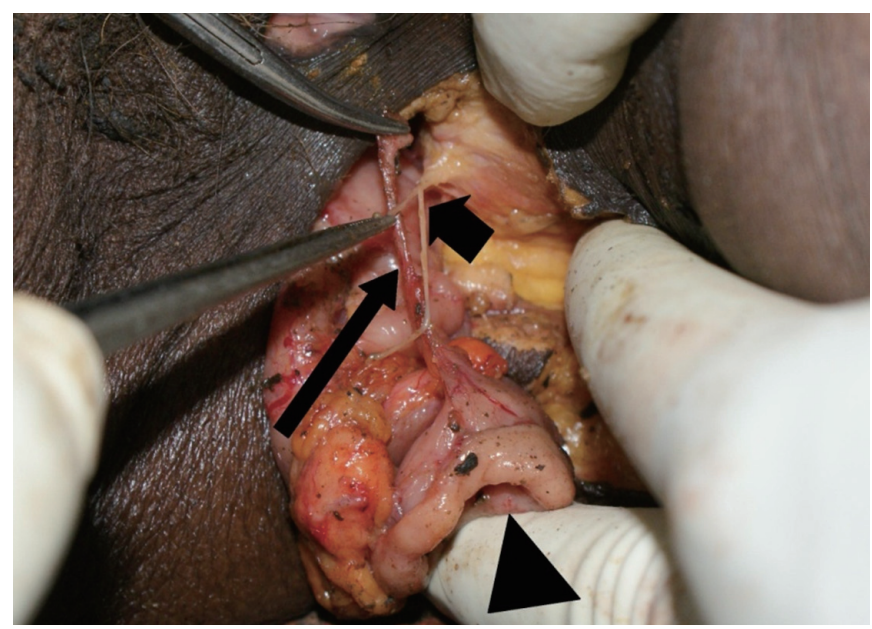

Fig. 3. Pylorus graft (arrow head) with the pyloric branch of the anterior vagus nerve (long arrow) in proximity to the inferior rectal nerves (short arrow) in the perineum. 


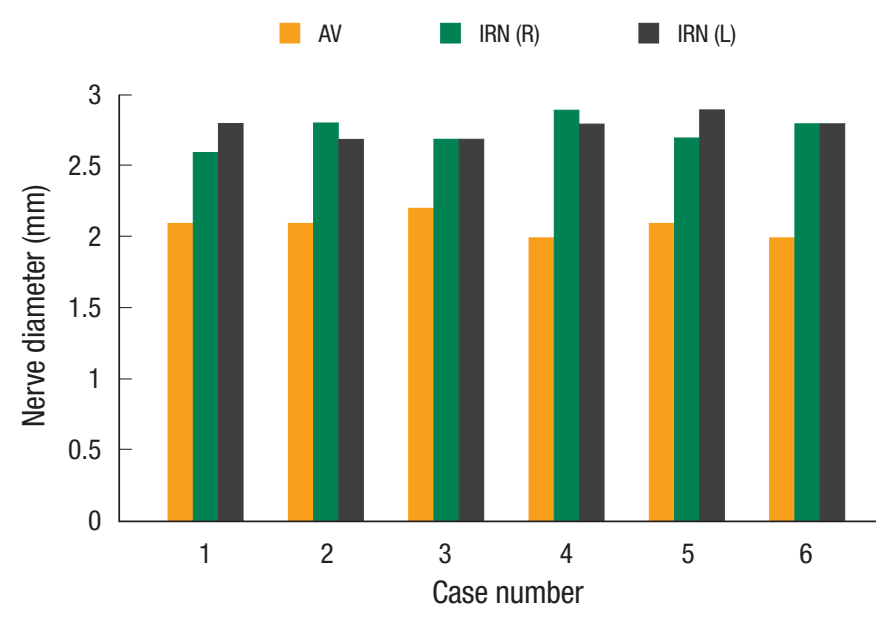

Fig. 4. Histogram showing the diameters of the anterior vagus (pyloric branch) and the inferior rectal nerves in the study group. AV, anterior vagus; IRN (R), right inferior rectal nerve; IRN (L), left inferior rectal nerve.

\section{RESULTS}

The mean age of cadavers was 56 years (range, 48 to 65 years), and the mean weight was $60.33 \mathrm{~kg}$ (range, 54 to $66 \mathrm{~kg}$ ). The branching pattern of the AV permitted its harvesting with the mobilized APV segment in all cadavers. A free length of 2.5 to $3 \mathrm{~cm}$ of the $\mathrm{AV}$ trunk below the hepatic division could be obtained in all six cadavers. The mean diameters of the $\mathrm{AV}$, the right IRN and the left IRN were $2.083 \pm 0.075 \mathrm{~mm}$ (range, 2.0 to $2.2 \mathrm{~mm}$ ), $2.75 \pm 0.10 \mathrm{~mm}$ (range, 2.6 to $2.9 \mathrm{~mm}$ ) and $2.783 \pm 0.075 \mathrm{~mm}$ (range, 2.7 to $2.9 \mathrm{~mm}$ ), respectively, as measured with engineering calipers (Fig. 4). In two cadavers, an additional branch to the pylorus emerged from hepatic division and could be harvested separately.

In the perineum, after excision of the anorectum, the IRN and its branches could be dissected within the ischioanal fossa in all cadavers, consistently around the 3 or the 9 oclock positions (Fig. 5). The IRN or its branches were of sufficient thickness in this position to enable a neural anastomosis. Carefully examination of the twelve sides of the perineum revealed that the nerves to the EAS followed a radial distribution, but without any constant pattern. We could achieve a tension-free approximation of the nerve supply (AV branch) of the perineally-transposed APV segment with the IRN or its branches in the perineum in all cadavers (Fig. 3).

\section{DISCUSSION}

A permanent abdominal colostomy after an APR of the anorectum for malignancy is a devastating consequence for the patient. Treatment options like stimulated gracilis muscle transplants and artificial anal sphincter implants have suboptimum results and lack desirable voluntary control $[2,3,13,14]$. Experimentally, a canine model showed that PN innervation of a skeletal-muscle anal wrap

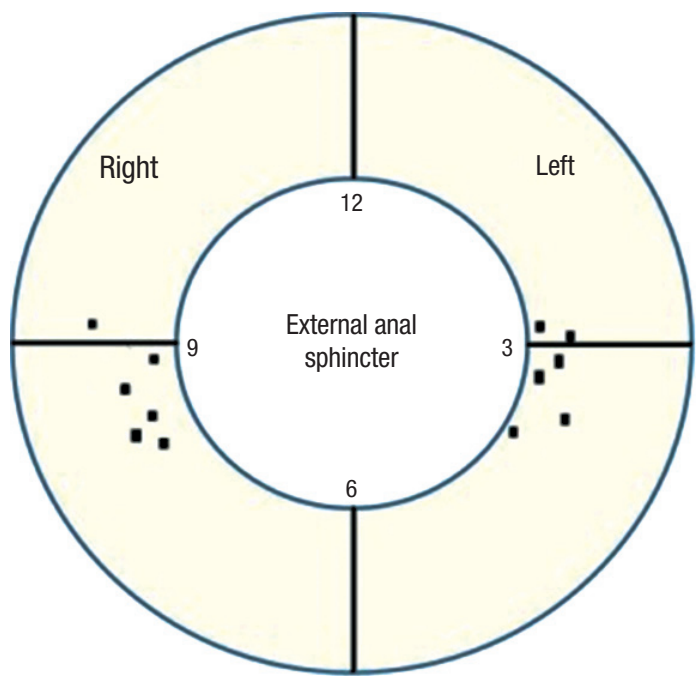

Fig. 5. Schematic representation of the position of the inferior rectal nerves in the ischioanal fossa in relation to the external anal sphincter (as seen from the perineum).

for producing a functional anal sphincter was superior to an electrically-stimulated passive wrap $[8,15]$. The gluteus maximus neoanus in humans with a PN anastomosis after an APR has shown better continence and control, but requires long-term validation [9].

In comparison to skeletal muscles, smooth muscles can provide prolonged tonic contraction with little fatigue and can shorten by a greater percentage of the initial length while maintaining the full force of contraction [16]. Therefore, smooth muscles can serve as better sphincter replacements physiologically. Preliminary studies on the use of APV transposition in the perineum following a resected or damaged anal sphincter (as a substitute for an abdominal stoma in humans) have recently accomplished this $[5,11]$. The transposed pyloric valve (smooth muscle) was shown to behave as a tonic sphincter when removed from the gastroduodenal continuity, with a median pressure of $30 \mathrm{mmHg}$ on manometry [17]. However, a marked difference in the outcomes occurred among patients who underwent this procedure for benign conditions as compared to APV transposition after an APR. Lack of voluntary control and poor sensation are problems in the latter group of patients due to excision of the entire sensate anorectum [6]. In order to circumvent this, we considered the feasibility of harvesting the $\mathrm{AV}$ nerve supply to the APV segment and bringing it down to the perineum along with the gastroepiploic vascular pedicle (Figs. 6A and $1 \mathrm{~B})$. In turn, this nerve (AV) to the APV segment was approximated to the IRN (PN) or its branches (Figs. 6B and 3) in the perineum, thus establishing a connection with the spinal defecation center. Carr and Brooks [18] experimentally demonstrated that electrical stimulation of the anterior vagii could cause sustained antral contractions. Therefore, the neural anastomosis thus effected between the $\mathrm{AV}$ and the IRN could also lead to neural con- 


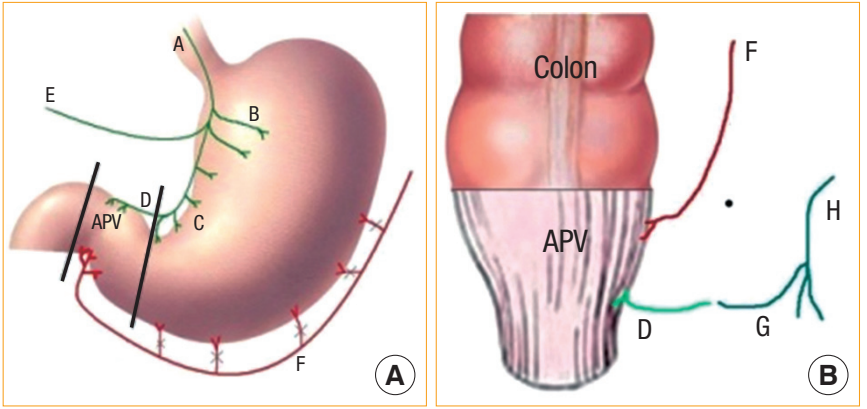

Fig. 6. Schematic drawings of the abdominal (A) and the perineal (B) steps of the procedure. Black lines indicate sites of division. APV, antropyloric valve; $A$, anterior vagus; $B$, gastric branches; $C$, crows foot; $\mathrm{D}$, pyloric branch; E, hepatic branch; F, gastroepiploic arcade; $\mathrm{G}$, inferior rectal nerve; $\mathrm{H}$, pudendal nerve.

trol of the transposed APV segment in the perineum. The vagus nerve branches act as a mere conduit for the regenerating axonal sprouts of IRN branches for future innervation of the APV. Thus, the APV will, in fact, be innervated by the PN branches (IRN). Concerns do remain about the IRN's innervating this APV segment, which is not a skeletal muscle.

The nerve supply to the pylorus usually comes from the AV via its anterior gastric division, nerve of Latarjet or descending branch of the hepatic division [19,20]. The AV trunk supplying the APV segment could be readily harvested in all dissections, providing sufficient length for nerve anastomosis (with IRN) in the perineum. One may need to take a greater part of the antrum by dividing the stomach more proximally in order to obtain a thicker AV. This would also be adding to the 'colonic reservoir' capacity of the 'pelvic' pylorus $[6,21]$.

The PN originates from S2-S4 nerve roots in the sacral plexus, traverses Alcock's canal and ischioanal fossa, and then gives off branches to the EAS [22-25]. Literature describing the details of EAS innervation is scarce. The nerve supply of the EAS has been shown to be radially distributed into three groups-anterior (ventral), middle, and posterior (caudal) parts, depending on the part of the EAS being supplied $[23,26]$. In our limited dissection, though this radial pattern could be ascertained, no definite three-tier distribution could be identified. However, the IRN and its branches were consistently found around the 3 or the 9 oclock position and could be readily dissected by us, as described by Gagnard et al. [26]. The APV segment based on its epiploic vascular arcade, along with its AV nerve supply, could be transposed to the pelvis, and the AV nerve could be approximated to the IRN or its branches at both these positions ( 3 and 9 o'clock) in the perineum in all cadavers.

Though the technique is anatomically feasible, issues related to neural vascularity and regeneration may affect the final outcome in terms of neural control of the perineally-transposed APV segment. Reported rates of axonal regeneration vary broadly from 0.5 to $9 \mathrm{~mm}$ per day [27]. Post regeneration, APV (smooth-muscle) contraction is expected to result from stimuli through the PN (a mixed nerve), which innervates a skeletal muscle. Physiological success of this parasympathetic motor (autonomic) nerve anastomosis to a somatic efferent nerve, although doubtful, has recently been shown to be feasible [28]. Dong et al. [28], in their experiments on anorectal reinnervation in animals, have demonstrated the success of somatic motor axon in-growth into an autonomic nerve through collateral sprouting after performing an end-toside neurorrhaphy. Research on neural repair has also shown successful neural regeneration across numerous nerve guidance conduits $[27,29]$. These aid the end-organ specific growth of regenerating axonal sprouts without resistance from intervening tissues. The AV would serves as a conduit for the regenerating axonal sprouts of the IRN and, in fact, the perineally-transposed APV segment will be innervated by the PN.

In conclusion, the APV segment can be transposed to the perineum along with its AV branch, followed by approximation of the $\mathrm{AV}$ with the IRN in the perineum after anorectal excision in all cadavers. Concerns regarding the neural vascularity of the transposed segment and the biological success of neural regeneration need further evaluation.

\section{CONFLICT OF INTEREST}

No potential conflict of interest relevant to this article was reported.

\section{ACKNOWLEDGMENTS}

We acknowledge the editing assistance of Dr. Animesh Chandra, Science Writer, Institute for Translational Sciences, University of Texas Medical Branch, Galveston, TX, USA.

\section{REFERENCES}

1. Sato T, Konishi F, Endoh N, Uda H, Sugawara Y, Nagai H. Longterm outcomes of a neo-anus with a pudendal nerve anastomosis contemporaneously reconstructed with an abdominoperineal excision of the rectum. Surgery 2005;137:8-15.

2. Tjandra JJ, Lim JF, Matzel K. Sacral nerve stimulation: an emerging treatment for faecal incontinence. ANZ J Surg 2004;74:1098-106.

3. Madoff RD, Baeten CG, Christiansen J, Rosen HR, Williams NS, Heine JA, et al. Standards for anal sphincter replacement. Dis Colon Rectum 2000;43:135-41.

4. Kang SB, Lee TG. Muscle regeneration: research for the treatment of fecal incontinence. J Korean Soc Coloproctol 2010;26:1-7.

5. Goldsmith HS, Chandra A. Pyloric valve transposition as substitute for a colostomy in humans: a preliminary report. Am J Surg 2011;202:409-16.

6. Chandra A. Reply to: Should we, not could we? A commentary on "Pyloric valve transposition as substitute for a colostomy in humans: a preliminary report”. Am J Surg 2012;204:806-7.

7. Mander BJ, Abercrombie JF, George BD, Williams NS. The electrically stimulated gracilis neosphincter incorporated as part of 
total anorectal reconstruction after abdominoperineal excision of the rectum. Ann Surg 1996;224:702-9.

8. Congilosi SM, Johnson DR, Medot M, Tretinyak A, McCormick SR, Wong WD, et al. Experimental model of pudendal nerve innervation of a skeletal muscle neosphincter for faecal incontinence. Br J Surg 1997;84:1269-73.

9. Sato T, Konishi F, Kanazawa K. Functional perineal colostomy with pudendal nerve anastomosis following anorectal resection: a cadaver operation study on a new procedure. Surgery 1997;121: 569-74.

10. Sato T, Konishi F, Kanazawa K. Anal sphincter reconstruction with a pudendal nerve anastomosis following abdominoperineal resection: report of a case. Dis Colon Rectum 1997;40:1497-502.

11. Chandra A, Gupta V, Kumar M, Parihar A, Kumar A, Jauhari R, et al. Anatomical basis of antropyloric transposition for fecal incontinence in humans: the infrapyloric approach. Surg Radiol Anat 2013;35:67-74.

12. O’Bichere A, Green C, Phillips RK. New, simple approach for maximal pudendal nerve exposure: anomalies and prospects for functional reconstruction. Dis Colon Rectum 2000;43:956-60.

13. Lehur PA, Michot F, Denis P, Grise P, Leborgne J, Teniere P, et al. Results of artificial sphincter in severe anal incontinence: report of 14 consecutive implantations. Dis Colon Rectum 1996;39: 1352-5.

14. Madoff RD, Rosen HR, Baeten CG, LaFontaine LJ, Cavina E, Devesa $M$, et al. Safety and efficacy of dynamic muscle plasty for anal incontinence: lessons from a prospective, multicenter trial. Gastroenterology 1999;116:549-56.

15. Sato T, Konishi F. Functional perineal colostomy with pudendal nerve anastomosis following anorectal resection: an experimental study. Surgery 1996;119:641-51.

16. Ratani RS, Yazaki E, Scott M, Pilot MA, Williams NS. Electrically stimulated smooth muscle neosphincter. Br J Surg 1997;84:1286-9.

17. Chandra A, Ghoshal UC, Gupta V, Jauhari R, Srivastava RN, Misra $\mathrm{A}$, et al. Physiological and functional evaluation of the trans- posed human pylorus as a distal sphincter. J Neurogastroenterol Motil 2012;18:269-77.

18. Carr DH, Brooks FP. Vagally induced gastric antral contractions and gastric emptying of a liquid test meal. Q J Exp Physiol Cogn Med Sci 1978;63:49-58.

19. Skandalakis JE, Gray SW, Soria RE, Sorg JL, Rowe JS Jr. Distribution of the vagus nerve to the stomach. Am Surg 1980;46:130-9.

20. Skandalakis LJ, Gray SW, Skandalakis JE. The history and surgical anatomy of the vagus nerve. Surg Gynecol Obstet 1986;162:75-85.

21. Fleshman JW. Should we, not could we? A commentary on "Pyloric valve transposition as substitute for a colostomy in humans: a preliminary report”. Am J Surg 2011;202:417-8.

22. Olszewski J. Variations of the pudendal nerve in man. Folia Morphol (Warsz) 1982;41:245-52.

23. Stefanski L, Lampe P, Aleksandrowicz R. The probability of finding nerve branches to the external anal sphincter. Surg Radiol Anat 2008;30:675-8.

24. Wunderlich M, Swash M. The overlapping innervation of the two sides of the external anal sphincter by the pudendal nerves. J Neurol Sci 1983;59:97-109.

25. Shafik A. Neuronal innervation of urethral and anal sphincters: surgical anatomy and clinical implications. Curr Opin Obstet Gynecol 2000;12:387-98.

26. Gagnard C, Godlewski G, Prat D, Lan O, Cousineau J, Maklouf Y. The nerve branches to the external anal sphincter: the macroscopic supply and microscopic structure. Surg Radiol Anat 1986;8:115-9.

27. Burnett MG, Zager EL. Pathophysiology of peripheral nerve injury: a brief review. Neurosurg Focus 2004;16:E1.

28. Dong C, Gao W, Jia R, Li S, Shen Z, Li B. Reconstruction of anorectal function through end-to-side neurorrhaphy by autonomic nerves and somatic nerve in rats. J Surg Res 2012 Apr 12 [Epub]. http://dx.doi.org/ 10.1016/j.jss.2012.03.053.

29. Wolford LM, Stevao EL. Considerations in nerve repair. Proc (Bayl Univ Med Cent) 2003;16:152-6. 